\title{
Frictional resistance of orthodontic wires tied with 3 types of elastomeric ligatures
}

\section{Amanda Carneiro da Cunha ${ }^{(a)}$ Mariana Marquezan ${ }^{(a)}$ \\ Amanda Osório Ayres de Freitas ${ }^{(a)}$ Lincoln Issamu Nojima ${ }^{(a)}$}

(a) Department of Orthodontics, School of Dentistry, Federal University of Rio de Janeiro, Rio de Janeiro, RJ, Brazil.
Declaration of Interests: The authors certify that they have no commercial or associative interest that represents a conflict of interest in connection with the manuscript.

\section{Corresponding author:}

Lincoln Issamu Nojima

E-mail: linojima@gmail.com

Received for publication on May 26, 2011 Accepted for publication on Aug 08, 2011

\begin{abstract}
The aims of this study were to determine and compare frictional resistance obtained by low-friction and conventional elastomeric ligatures in the presence of artificial saliva, and observe whether this variable changed after 21 days. Super Slick ${ }^{\circledR}$ low-friction elastomeric ligatures and conventional ligatures of the brands TP conventional ${ }^{\circledR}$ and Unitek $^{\circledR}$ were placed on standard edgewise maxillary central incisor metal brackets, slot $.022^{\prime \prime} \times .028 "$ tying rectangular orthodontic wires $.018 " \times .025 "$. Three experimental groups were arranged according to the type of ligature and a control group in which no wires were used. The friction values obtained between the bracket/wire/ligature set were measured using a Universal Test Machine at a speed of $20 \mathrm{~mm} /$ minute, at two experimental time intervals: T0 - immediately after specimen fabrication; and T1 - 21 days after fabrication and immersion in artificial saliva at $37^{\circ} \mathrm{C}$. Conventional Unitek ligatures and the low-friction ligature (Super Slick) showed the lowest friction values at T0. After 21 days (T1), however, conventional Unitek ligatures presented the lowest value. All groups assessed from T0 to T1 showed a numerical reduction in friction values, suggesting that time, heat and humidity may cause elastic degradation, however this was not verified statistically $(\mathrm{P}>0.05)$.
\end{abstract}

Descriptors: Friction; Saliva, Artificial; Orthodontics.

\section{Introduction}

During sliding mechanics in Orthodontic treatment, part of the applied force is dissipated to overcome friction, while another fraction is transmitted to the tooth supporting structures inducing tooth movement. Therefore, to obtain appropriate tooth movement, the total force will be determined by the optimum force to move the tooth, as well as force needed to overcome friction between the bracket and orthodontic wire. ${ }^{1-4}$ There are situations in which different friction intensities are needed. A low friction coefficient is necessary in cases of retraction of teeth or space closure, whereas for anchorage, a high friction coefficient is more appropriate. $^{5}$

The method of tying orthodontic wires to the brackets also influences the amount of friction obtained. ${ }^{6}$ Elastomeric ligatures have become an integral part of orthodontic clinical practice. ${ }^{7}$ The advantages are as follows:

\footnotetext{
- ease of application,
} 
- comfort for the patient,

- availability of a variety of colors, and

- less chair time.

Amongst the disadvantages there are:

- higher bacterial accumulation on teeth and surfaces adjacent to brackets,

- the probability of orthodontic wire not completely seating during corrections involving torque or speed and

- the possibility of bending the wire during orthodontic sliding mechanics. ${ }^{8-10}$

There are low-friction elastomeric ligatures which, according to the manufacturers, have a highly lubricated surface, so that they become extremely slippery when wet, thereby reducing friction. In 2000, a polymeric-coated ligature, Super Slick ${ }^{\circledR}$ (TP Orthodontics, La Porte, USA), was introduced on the orthodontic market with the purpose of significantly reducing friction. ${ }^{4,11,12}$ The latest studies conducted with low-friction ligatures showed differences between the results of the friction produced by these elastomeric ligatures and conventional ligatures. ${ }^{4,11-16}$

Therefore, the aim of this study was to compare frictional resistance obtained by low-friction elastomeric ligatures and conventional ligatures in the presence of artificial saliva, and observe whether this variable changed after 21 days.

\section{Methodology}

Three types of elastomeric ligatures were assessed: a low-friction ligature, Super Slick ${ }^{\circledR}$ (TP Orthodontics, La Porte, USA), and two conventional ligatures, $\mathrm{TP}^{\circledast}$ (TP Orthodontics, La Porte, USA) and Unitek ${ }^{\circledR}(3 \mathrm{M}$, Monrovia, USA), forming three experimental groups according to the type of ligature used, and a control group in which no tying between wire and bracket was used (Table 1).

Standard edgewise maxillary central incisor metal brackets (slot .022" ×.028") from American Orthodontics (American Orthodontics, Sheboygan, USA) were fixed in the center of acrylic cylinders (10 mm radius) using cyanoacrylate (Super Bonder ${ }^{\circledR}$, Henkel Ltda., São Paulo, Brazil). The acrylic cylinder was adapted to a device fixed to the lower portion of the universal test machine (EMIC - DL 2000, EMIC Equipamentos e Sistemas de Ensaio Ltda., São José dos Pinhais, Brazil). Another device was adapted to the upper portion of the machine

Table 1 - Design of control and experimental groups.

\begin{tabular}{c|c}
\hline Group & Ligature \\
\hline GC & Control Group - no tying of wire to bracket \\
\hline GTP & Conventional TP ligature \\
\hline GTPSS & Super Slick TP ligature \\
\hline G3M & $3 M /$ Unitek conventional ligature \\
\hline
\end{tabular}

Figure 1 - Frictional test.

a) Devices adapted to the universal test machine; b) close-up of the specimen adapted to the device during the test.
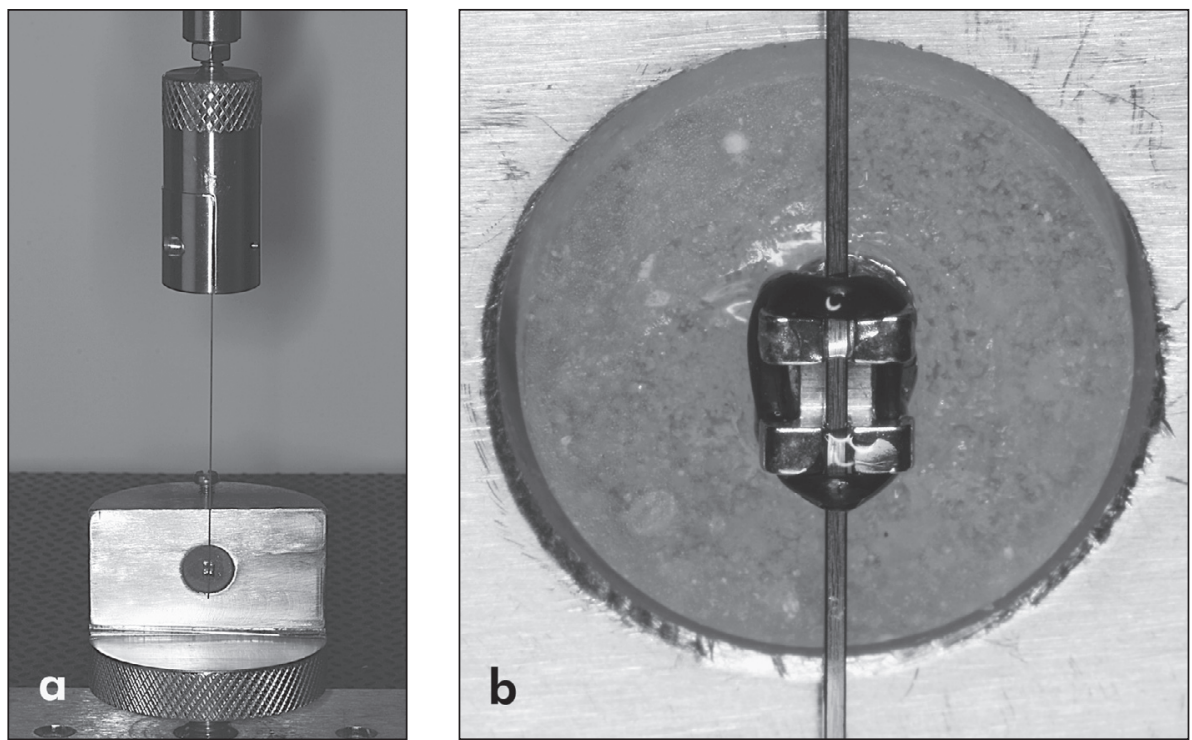
Table 2 - Values of frictional resistance shown by the groups at time TO.

\begin{tabular}{c|c|c}
\hline Group/Time & Mean (N) & Standard Deviation \\
\hline GC & $0.35 a$ & 0.13 \\
\hline GTP & $3.87 b$ & 0.77 \\
\hline GTPSS & $3.60 b, c$ & 0.43 \\
\hline G3M & $3.26 c$ & 0.56 \\
\hline
\end{tabular}

Different letters indicate a statistical difference at $\alpha=0.05 \%$ (ANOVA) Tukey).

and a $10-\mathrm{cm}$ rectangular orthodontic wire segment $\left(.018 " \times .025^{\prime \prime}\right.$ - Orthodontics Morelli, Sorocaba, Brazil) was attached to it to slide in the bracket slot during the test (Figure 1). The friction test was conducted at a speed of $20 \mathrm{~mm} /$ minute. ${ }^{12}$ Friction was measured in Newtons $(\mathrm{N})$ and calculated by the mean obtained between the beginning and the end of motion. ${ }^{17}$

Sixty test specimens were fabricated and randomly placed in the 4 groups, according to the sample calculation for the difference among the means $(\alpha=5 \%$, power of study $=80 \%)$. Two experimental time intervals were assessed: T0 - immediately after test specimen fabrication; and T1 - 21 days after fabrication and immersion in artificial saliva at $37{ }^{\circ} \mathrm{C} .1^{18}$ Each specimen consisted of an acrylic cylinder, a metal bracket, a $10-\mathrm{cm}$ wire segment and a ligature. The entire set was immersed in saliva for T1.

Statistical analysis was performed with the Statistical Package program for Social Science (version 17, SPSS Inc., Chicago, USA). Verification of normality and homogeneity was performed using the Shapiro-Wilk test and Levene test, respectively. After verifying normal and homogeneous distribution of variables, the analysis of variance (ANOVA) and Tukey's multiple comparison tests were used to detect inter-group differences. The paired Student's- $t$ test was applied to compare intra-group differences over the time intervals. The level of significance adopted was $0.05 \%$.

\section{Results}

The results of the friction test for the groups assessed at times T0 and T1 are shown in Tables 2 and 3, respectively. At T0, G3M and GTPSS presented
Table 3 - Values of frictional resistance shown by the groups at time $T 1$.

\begin{tabular}{c|c|c}
\hline Group/Time & Mean (N) & Standard Deviation \\
\hline GC & $0.24 a$ & 0.68 \\
\hline GTP & $1.68 b$ & 0.35 \\
\hline GTPSS & $1.68 b$ & 0.31 \\
\hline G3M & $1.24 c$ & 0.51 \\
\hline
\end{tabular}

Different letters indicate a statistical difference at $\alpha=0.05 \%$ (ANOVA) Tukey).

Table 4 - Paired Student's-t test used to compare each group over time.

\begin{tabular}{c|c|c|c}
\hline Group & Mean (N) TO & Mean (N) T1 & T-test \\
\hline GC & 0.35 & 0.24 & $P=1.0$ \\
\hline GTP & 3.87 & 1.68 & $P=0.874$ \\
\hline GTPSS & 3.60 & 1.68 & $P=0.252$ \\
\hline G3M & 3.26 & 1.24 & $P=0.13$ \\
\hline
\end{tabular}

the lowest friction values. At T1, however G3M presented the lowest value. The intra-group comparison over time is presented in Table 4. A numerical reduction in friction values was observed from $\mathrm{T} 0$ to $\mathrm{T} 1$; however it was not statistically significant.

\section{Discussion}

Obtaining adequate force during orthodontic treatment will certainly result in an optimal tissue response and satisfactory tooth movement. During movement of the bracket along the wire, friction at the bracket-wire interface may prevent the attainment of adequate force levels. Therefore, understanding the forces required to overcome friction is important, since it will allow the use of an appropriate magnitude of force to produce the desired tooth movement. . $^{2,3,13}$

To examine the nature of friction between the wire and bracket, variables such as bracket material, type of alloy and wire section should be taken into consideration. ${ }^{3,13,19}$ In the present study, standard edgewise maxillary central incisor metal brackets (slot .022" $\times .028 ")$ were used (American Orthodontics, Sheboygan, USA). The reason for choosing edgewise brackets was because the slots were flat 
and they could be mounted without inclination or angulation. ${ }^{17}$ Rectangular stainless steel orthodontic wire sections $.018 " \times .025 "$ were chosen because they are useful during sliding mechanics. These wires do not undergo as much deflection as lighter wires, however, they show a lower friction coefficient when compared with the thicker ones, ${ }^{1,17,20,21}$ since the larger the wire size, the higher the friction coefficient. ${ }^{1,6,20,22}$

The method of wire ligation to the bracket also influences frictional resistance ${ }^{23}$ and it is proportional to the ligation force and friction coefficient of the surfaces that are in contact. ${ }^{24}$ Therefore, this study was developed with the purpose of comparing the frictional resistance produced by different elastomeric ligatures, one low-friction ligature and two conventional ligatures, since they are the first choice of several orthodontists. ${ }^{17}$ Elastomeric ligatures are made of polyurethane-based polymers which, when submitted to stress, undergo a loosening process (molecular reorientation and permanent deformation) and small amount of hydrolytic decomposition over a period of time. ${ }^{25,26}$

The results of this study showed that when considering the friction coefficient, the Super Slick ligatures present no advantages in comparison with conventional ligatures. When tested immediately (T0), the GTPSS presented a similar friction value to G3M. After 21 days, G3M presented the lowest friction coefficient. Similar results were reported by Khambay et al. ${ }^{4}$, Khambay et al. ${ }^{16}$ and Griffiths et al. ${ }^{11}$ who observed no improvement in friction value by using low-friction ligatures. On the other hand, some previous studies have shown that low-friction ligatures can significantly reduce friction during sliding mechanics. ${ }^{12,13,14,15}$ Comparison of the results obtained by different studies must be made carefully and the following methodological differences should be taken into consideration: use of different brackets, wires and means of lubrication.

With regard to the reduction in friction over the time interval, all the experimental groups showed a numerical reduction; however, this was not confirmed statistically. Taloumis et al. ${ }^{10}$ reported that the regular modules are altered by the presence of humidity and heat, showing a reduction in friction coefficient over a period of time. The lowest numerical reduction in mean values between $\mathrm{T} 0$ and $\mathrm{T} 1$ was observed for GTPSS. This may be explained by the presence of a covering layer on Super Slick elastomeric ligatures, which acts as protection against the effects of humidity and heat. ${ }^{12}$

When analyzing the methodology used, it may be observed that conducting the study in the presence of humidity, and for the time interval during which the test specimens remained exposed to saliva, were factors that contributed positively to obtaining results in an environment that more closely simulated that of the oral cavity. Nevertheless, all the limitations that involve in vitro studies should be taken into consideration, such as the presence of masticatory forces, tooth movement during orthodontic treatment and biological factors involved, such as the presence of bacterial plaque and acquired pellicle. ${ }^{1}$ Furthermore, the presence of some components of the artificial saliva used in the present study might have contributed to defining the degradation profile of elastomeric ligatures, which may be different if other means of lubrication were used.

The results obtained in the present study may indicate the choice of elastomeric ligatures in clinical practice when different friction levels are required. However, further studies using different means of lubrication, such as human and artificial saliva, are needed. Thus, it would be possible to assess the degrees of influence that the type of environment has on the friction coefficients obtained.

\section{Conclusions}

- GTPSS and G3M showed lower friction values at T0. However, G3M showed the lowest value after 21 days (T1).

- Although no statistical difference was observed in the intra-group comparison over time, the numerical reduction in friction values observed in all of the groups from $\mathrm{T} 0$ to $\mathrm{T} 1$ suggests that time, heat and humidity may cause elastic degradation.

\section{Acknowledgements}

The authors would like to thank FAPERJ for financial support. 


\section{References}

1. Kapila S, Angolkar PV, Duncanson MG, Nanda RS. Evaluation of friction between edgewise stainless steel brackets and orthodontic wires of four alloys. Am J Orthod Dentofacial Orthop. 1990 Aug;98(2):117-26.

2. Ogata RH, Nanda RS, Duncanson MG, Sinha PK, Currier GF. Frictional resistances in stainless steel bracket-wire combinations with effects of vertical deflections. Am J Orthod Dentofacial Orthop. 1996 May;109(5):535-42.

3. Cacciafesta V, Sfondrini MF, Ricciardi A, Scribante A, Klersy C, Auricchio F. Evaluation of friction of stainless steel and esthetic self-ligating brackets in various bracket-archwire combinations. Am J Orthod Dentofacial Orthop. 2003 Oct;124(4):395-402.

4. Khambay B, Millett D, McHugh S. Evaluation of methods of archwire ligation on frictional resistance. Eur J Orthod. 2004 Jun;26(3):327-32.

5. Burrow SJ. Friction and resistance to sliding in orthodontics: a critical review. Am J Orthod Dentofacial Orthop. 2009 Apr;135(4):442-7.

6. Ehsani S, Mandich MA, El-Bialy TH, Flores-Mir C. Frictional resistance in self-ligating orthodontic brackets and conventionally ligated brackets - A Systematic Review. Angle Orthod. 2009 May;79(3):592-601.

7. Baty DL, Storie DJ, Fraunhofer JA. Synthetic elastomeric chains: a literature review. Am J Orthod Dentofacial Orthop. 1994 Jun;105(6):536-42.

8. Forsberg CM, Brattström V, Malmberg E, Nord CE. Ligature wires and elastomeric rings: two methods of ligation, and their association with microbial colonization of Streptococcus mutans and lactobacilli. Eur J Orthod. 1991 Oct;13(5):416-20.

9. Bednar JR, Gruendeman GW. The influence of bracket design on moment production during axial rotation. Am J Orthod Dentofacial Orthop. 1993 Sep;104(3):254-61.

10. Taloumis LJ, Smith TM, Hondrum SO, Lorton L. Force decay and deformation of orthodontic elastomeric ligatures. Am J Orthod Dentofacial Orthop. 1997 Jan;111(1):1-11.

11. Griffiths HS, Sherriff M, Ireland AJ. Resistance to sliding with 3 types of elastomeric modules. Am J Orthod Dentofacial Orthop. 2005 Jun;127(6):670-5.

12. Hain M, Dhopatkar A, Rock P. A comparison of different ligation methods on friction. Am J Orthod Dentofacial Orthop. 2006 Nov;130(5):666-70.

13. Tecco S, Di lorio D, Cordasco G, Verrochi I, Festa F. An in vitro investigation of the influence of self-ligating brackets, low friction ligatures, and archwire on frictional resistance. Eur J Orthod. 2007 Aug;29(4):390-7.
14. Hain M, Dhopatkar A, Rock P. The effect of ligation method on friction in sliding mechanics. Am J Orthod Dentofacial Orthop. 2003 Apr;123(4):416-22.

15. Gandini P, Orsi L, Bertoncini C, Massironi S, Franchi L. In vitro frictional forces generated by three different ligation methods. Angle Orthod. 2008 Sep;78(5):917-21.

16. Khambay B, Millett D, McHugh S. Archwire seating forces produced by different ligation methods and their effect on frictional resistance. Eur J Orthod. 2005 Jun;27(3):302-8.

17. Marques IS, Araújo AM, Gurgel JA, Normando D. Debris, roughness and friction of stainless steel archwires following clinical use. Angle Orthod. 2010 May;80(3):521-7.

18. Lin MC, Lin SC, Lee TH, Huang HH. Surface analysis and corrosion resistance of different stainless steel orthodontic brackets in artificial saliva. Angle Orthod. 2006 Mar;76(2):322-9.

19. Tanne K, Matsubara S, Shibaguchi T, Sakuda M. Wire friction from ceramic brackets during simulated canine retraction. Angle Orthod. 1991 Winter;61(4):285-92.

20. Drescher D, Bourauel C, Schumacher HA. Frictional forces between bracket and arch wire. Am J Orthod Dentofacial Orthop. 1989 Nov; 96(5):397-404.

21. Mendes K, Rossouw PE. Friction: validation of the manufacturer's claim. Semin Orthod. 2003 Dec;9(4):236-50.

22. Tecco $S$, Tetè $S$, Festa F. Friction between archwires of different sizes, cross-section and alloy and brackets ligated with low-friction or conventional ligatures. Angle Orthod. 2009 Jan;79(1):111-6.

23. Berger JL. The influence of the SPEED bracket's self-ligating design on force levels in tooth movement: a comparative in vitro study. Am J Orthod Dentofacial Orthop. 1990 Mar;97(3):219-28.

24. Thorstenson GA, Kusy RP. Comparison of resistance to sliding between different self-ligating brackets with second-order angulation in the dry and saliva states. Am J Orthod Dentofacial Orthop. 2002 May;121(5):472-82.

25. Thomas S, Sherriff M, Birnie D. A comparative in vitro study of the frictional characteristics of two types of self-ligating brackets and two types of pre-adjusted edgewise brackets tied with elastomeric ligatures. Eur J Orthod. 1998 Oct;20(5):58996.

26. Eliades T, Eliades G, Silikas N, Watts DC. Tensile properties of orthodontic elastomeric chains. Eur J Orthod. 2004 Apr;26(2):157-62. 